\title{
Pengaruh Pelatihan, Motivasi dan Disiplin Kerja Terhadap Kinerja Karyawan Dinas Pengamanan PT. Angkasa Pura II Pekanbaru
}

\author{
WIKE SYAFITRI \\ Dosen Tetap Sekolah Tinggi Ilmu Ekonomi Riau \\ Jln. HR. Subrantas 57 Panam Pekanbaru 28293 Telp. (0761) 63237 \\ E-mail : wike.syafitri@yahoo.co.id
}

\begin{abstract}
Improved knowledge, skills, change in attitudes, behavior, the correction of the deficiencies of performance needed to improve performance and productivity through training, motivation and discipline of the principal or company. Are the training, motivation and discipline this performance can affect the performance of the security service employees of PT. Angkasa Pura II Pekanbaru. The purpose of this study was to examine the effect of training, motivation and discipline on the performance of the security service employees of PT. Angkasa Pura II Pekanbaru. Methods of data analysis used multiple linear regression to test $\mathrm{t}$ and $\mathrm{f}$ test, test instrument validas, reliability, normality, multicollinearity, heteroskedasticity and the coefficient of determination. The results showed a partial training, and discipline significant effect on employee performance while motivation does not affect the performance of employees. Simultaneously independent variables affect the dependent variable.
\end{abstract}

Keywords: Training, Motivation, Work Discipline and Employee Performance

Perkembangan dunia bisnis di Indonesia sekarang ini perusahaan dituntut untuk mempertahankan dan meningkatkan kualitas kerja. Hal ini dimaksudkan agar perusahaan dapat bersaing dengan perusahaan lain yang sejenis, baik pada tingkat nasional maupun tingkat internasional. Salah satu bagian penting yang berperan dalam menentukan keberhasilan perusahaan adalah dengan pembinaan tenaga kerja yang potensial. Perusahaan berusaha mencari dan membina karyawan dengan semangat tinggi, menciptakan dan memelihara keunggulan sumber daya manusia yang mampu bersaing. Sumber daya manusia inilah yang pada akhirnya menjadi tulang punggung bagi keberhasilan suatu perusahaan.

Kualitas sumber daya manusia ditentukan oleh sejauh mana sistem dibidang sumber daya manusia ini sanggup menunjang dan memuaskan keinginan karyawan maupun perusahaan. Peningkatan pengetahuan, skill, perubahan sikap, perilaku, koreksi terhadap kekurangan-kekurangan kinerja dibutuhkan untuk meningkatkan kinerja dan produktivitas melalui pelatihan, motivasi dan disiplin kerja dari pimpinan atau perusahaan. Pelatihan akan memberikan kesempatan bagi karyawan mengembangkan keahlian dan kemampuan baru dalam bekerja agar apa yang diketahui dan dikuasai saat ini maupun masa mendatang dapat membantu karyawan untuk mengerti apa yang seharusnya dikerjakan dan mengapa harus dikerjakan, memberikan kesempatan untuk menambah pengetahuan, dan keahlian. Motivasi juga berperan dalam meningkatkan kinerja karyawan dengan motivasi akan memberikan kesempatan kepada karyawan untuk menyalurkan ego individu dan memperkuat komitmen karyawan pada perusahaan. Sedangkan peningkatan disiplin akan memberikan dampak yang baik pada kinerja karyawan seperti tingkat kehadiran, ketepatan dalam penyelesaian tugas, dan waktu yang diberikan sehingga target perusahaan dapat tercapai.

Secara etimologi, kinerja berasal dari kata prestasi kerja Sebagaimana dikemukan oleh Mangkunegara bahwa 
isitilah kinerja dari kata kata job performance atau actual performance (prestasi kerja atau prestasi sesungguhnya yang dicapai oleh seseorang) yaitu hasil kerja secara kualitas dan kuantitas yang dicapai oleh seorang pegawai dalam melaksanakan tugasnya sesuai dengan tanggung jawab yang diberikan padanya (Mangkunegara, 2007:77)

Pelatihan adalah proses pendidikan jangka pendek yang menggunakan prosedur yang sistematis dan terorganisir". Selanjutnya, Udai menyatakan : "Training and development is defined as the human recourse practice which focuced is identifying, assessing and through planned learning helping development the key competences which enable people to perform current or future job", these activities which are designed to improve human performance on the job employee is presently doing or is being hired to do".

Menurut Hasibuan Malayu S.P dalam Sunyoto Danang (2015:191) motivasi adalah suatu perangsang keinginan daya gerak kemauan bekerja seseorang, setiap motif mempunyai tujuan tertentu yang ingin dicapai.

Menurut Kuswadi, disiplin kerja diperlukan untuk menghasilkan kinerja yang bagus, dengan disiplin pegawai akan berusaha untuk melakukan pekerjaan semaksimal mungkin dan kinerja yang dihasilkan akan menjadi lebih bagus (Kuswadi, 2004:54).

Lubis (2008) meneliti pengaruh pelatihan dan motivasi kerja terhadap kinerja karyawan PT. Perkebunan Musantara IV (Persero) Medan. Populasi penelitian ini adalah seluruh karyawan pimpinan pria dan wanita di Kantor Pusat PT. Perkebunan Musantara IV (Persero) Medan yang berjumlah 155 orang. Hasil penelitian menunjukkan bahwa pelatihan dan motivasi kerja berpengaruh terhadap kinerja karyawan baik secara parsial maupun simultan. Nilai koefisien determinasi diperoleh sebesar $8,81 \%$.

Sanjaya (2015) dengan judul penelitian pengaruh disiplin kerja dan Jurnal Daya Saing motivasi kerja terhadap kinerja karyawan Hotel Ros In Yogyakarta. Populasi dalam penelitian sebanyak 115 orang karyawan Hotel Ros In Yogyakarta. Teknik sampel yang digunakan purposive sampling sehingga diperoleh sampel sebanyak 115 orang. Dari hasil penelitian menunjukkan bahwa secara parsial dan simultan disiplin kerja dan motivasi kerja berpengaruh positif dan signifikan terhadap kinerja karyawan.

Rumbewas (2016) meneliti mengenai analisis pengaruh pelatihan, motivasi dan disiplin kerja terhadap kinerja karyawan (studi pada karyawan Bank BRI Kantor Wilayah Jayapura). Sampel sebanyak 70 orang menggunakan teknik purposive sampling. Metode analisis data yang digunakan adalah metode regresi linier berganda. Berdasarkan hasil penelitian ini menunjukkan bahwa variabel pelatihan, motivasi dan disiplin kerja berpengaruh positif terhadap variabel kinerja karyawan.

\section{METODE}

Penelitian ini adalah penelitian sosial bersifat deskriptif kuantitatif. Adapun populasi pada penelitian ini adalah karyawan Dinas Pengamanan PT. Angkasa Pura II Pekanbaru berjumlah 135 orang karyawan. Karena populasi lebih dari 100 orang, maka penarikan sampel penelitian ini menggunakan sampel secara acak (random sampling).

Penyebaran angket dilakukan dan diberikan kepada karyawan Dinas Pengamanan PT. Angkasa Pura II Pekanbaru. Teknik pengukuran instrumen digunakan skala likert dengan skala ini, maka nilai variabel yang diukur dengan instrumen tertentu dapat dinyatakan dalam bentuk angka, sehingga akan lebih akurat, efisien dan komunikatif. Jawaban setiap item instrumen yang menggunakan skala likert mempunyai gradasi dari sangat positif sampai sangat negatif, yang dapat berupa kata-kata antara lain (Sugiyono, 2015:93) yaitu sangat setuju (5), Setuju 
kurang setuju (3), tidak setuju (2) dan sangat tidak setuju (1). Instrumen penelitian yang menggunakan skala likert dapat dibuat dalam bentuk checklist ataupun pilihan ganda.

Dalam penelitian ini untuk menguji hipotesis penelitian menggunakan analisis regresi linier berganda yaitu melihat pengaruh pelatihan, motivasi dan disiplin kerja terhadap kinerja karyawan, persamaan matematis analisis regresi linier berganda.

\section{HASIL}

Hasil uji validas dan reliabilitas variabel pelatihan (X1), motivasi (X2), disiplin kerja (X3) dan kinerja karyawan (Y) adalah valid dan relibel.

Hasil uji menunjukkan data berdistribusi normal dan bebas dari uji multikolinearitas, autokorelasi, dan heteroskedastisitas.

Untuk mengetahui arah variabel bebas yaitu pelatihan, motivasi dan disiplin kerja terhadap kinerja karyawan, dilakukan analisis statistik yaitu berupa regresi linier berganda. Berikut adalah output hasil SPSS :

Tabel 1 : Hasil Uji Analisis Regresi Linier Berganda

\begin{tabular}{|l|l|l|l|l|l|l|}
\hline \multirow{2}{*}{ Model } & \multicolumn{2}{|l|}{$\begin{array}{l}\text { Unstandardized } \\
\text { Coefficients }\end{array}$} & $\begin{array}{l}\text { Standardized } \\
\text { Coefficients }\end{array}$ & & \\
\cline { 2 - 6 } & B & $\begin{array}{l}\text { Std. } \\
\text { Error }\end{array}$ & Beta & t & Sig. \\
\hline \multirow{2}{*}{1} & (Constant) & 12.752 & 4.163 & & 3.063 & .003 \\
\cline { 2 - 5 } & Pelatihan & .368 & .158 & .258 & 2.325 & .024 \\
\hline Motivasi & .180 & .124 & .182 & 1.453 & .152 \\
\hline Disiplin & .661 & .195 & .413 & 3.385 & .001 \\
\hline
\end{tabular}

a. Dependent Variable: Kinerja

Sumber : Data Olahan SPSS

Berdasarkan tabel diatas maka dapat dijelaskan dalam bentuk persamaan yaitu : $\mathrm{Y}=12,752+0,368 \mathrm{X} 1+0,180 \mathrm{X} 2+0,661 \mathrm{X} 3$ Pengambilan keputusan pada uji $t$ berdasarkan nilai $t_{\text {hitung }}$ dengan nilai $t_{\text {tabel }}$ (nilai kritis) sesuai dengan tingkat kepercayaan $95 \%$ atau signifikansi level sebesar 5\% (0,05). Jika $t_{\text {hitung }}$ lebih besar dari $t_{\text {tabel }}$ maka hipotesis diterima dan jika $t_{\text {hitung }}$ lebih kecil dari $t_{\text {tabel }}$ maka hipotesis ditolak.

Tabel 2 : Hasil Uji t

\begin{tabular}{|c|c|c|c|c|c|}
\hline \multirow[b]{2}{*}{ Model } & \multicolumn{2}{|c|}{$\begin{array}{l}\text { Unstandardized } \\
\text { Coefficients }\end{array}$} & \multirow{2}{*}{$\begin{array}{c}\begin{array}{l}\text { Standardized } \\
\text { Coefficients }\end{array} \\
\text { Beta }\end{array}$} & \multirow[b]{2}{*}{$\mathrm{t}$} & \multirow[b]{2}{*}{ Sig. } \\
\hline & B & $\begin{array}{l}\text { Std. } \\
\text { Error }\end{array}$ & & & \\
\hline 1 (Constant) & 12.752 & 4.163 & & 3.063 & .003 \\
\hline Pelatihan & .368 & .158 & .258 & 2.325 & .024 \\
\hline Motivasi & .180 & .124 & .182 & 1.453 & .152 \\
\hline Disiplin & .661 & .195 & .413 & 3.385 & .001 \\
\hline
\end{tabular}

a. Dependent Variable: Kinerja

Sumber : Data Olahan SPSS

Berdasarkan hasil output SPSS pada tabel diatas diperoleh nilai $t_{\text {hitung }}$ untuk masing-masing variabel adalah pelatihan (X1) nilai t hitung $=2,325$ motivasi (X2) nilai t hitung $=1,453$ disiplin kerja $(X 3)$ nilai $\mathrm{t}$ hitung $=3,385$. Sedangkan untuk nilai t tabel 2,004 maka dapat disimpulkan bahwa secara parsial pelatihan dan disiplin kerja berpengaruh signifikan dengan kinerja karyawan Dinas Pengamanan PT. Angkasa Pura II Pekanbaru karena $t$ hitung $>\mathrm{t}$ tabel dengan tingkat signifikansi $0,05 \%$ sedangkan motivasi tidak berpengaruh signifikan terhadap kinerja karyawan Dinas Pengamanan PT. Angkasa Pura II Pekanbaru karena t hitung $<\mathrm{t}$ tabel.

Uji $F$ digunakan untuk melihat pengaruh antara variabel bebas terhadap variabel terikat secara bersama-sama, berikut adalah hasil dari SPSS :

Tabel 3 : Hasil Uji F

\begin{tabular}{|l|l|l|l|l|l|l|}
\hline \multicolumn{2}{|l|}{ Model } & $\begin{array}{l}\text { Sum of } \\
\text { Squares }\end{array}$ & df & $\begin{array}{l}\text { Mean } \\
\text { Square }\end{array}$ & F & Sig. \\
\hline 1 & Regression & 1178.826 & 3 & 392.942 & 14.696 & $.000^{\mathrm{a}}$ \\
\cline { 2 - 7 } & Residual & 1417.068 & 53 & 26.737 & & \\
\hline \multicolumn{2}{|l|}{ Total } & 2595.895 & 56 & & & \\
\hline
\end{tabular}

a. Predictors: (Constant), Disiplin, Pelatihan, Motivasi

b. Dependent Variable: Kinerja

Sumber : Data Olahan SPSS

Berdasarkan hasil SPSS diperoleh nilai $F$ hitung 14,696 maka dapat disimpulkan nilai $\mathrm{F}$ hitung 14,696 > F tabel 2,766 sehingga secara bersama-sama variabel bebas yaitu pelatihan, motivasi dan 
disiplin kerja berpengaruh signifikan terhadap variabel terikat yaitu kinerja karyawan.

Untuk melihat pengaruh variabel independen terhadap variabel dependen secara serentak dapat dinilai dari adjusted $R$ square nya, karena variabel yang dipakai lebih dari dua (Ghozali, 2001). Hasil adjusted $R$ square terlihat pada tabel berikut :

Tabel 4: Hasil Uji Koefisien Determinasi $\left(\mathrm{R}^{2}\right)$

\begin{tabular}{|c|c|c|c|c|}
\hline Model & $\mathrm{R}$ & $\begin{array}{l}\mathrm{R} \\
\text { Square }\end{array}$ & $\begin{array}{l}\text { Adjusted } \\
\text { Square }\end{array}$ & \begin{tabular}{l|l}
$\mathrm{R}$ & $\begin{array}{l}\text { Std. Error of the } \\
\text { Estimate }\end{array}$
\end{tabular} \\
\hline 1 & $.674^{\mathrm{a}}$ & .454 & .423 & 5.17080 \\
\hline
\end{tabular}

Dari tabel 4 dapat dilihat bahwa nilai adjusted $R$ square dari model penelitian ini adalah $0,454(45,4 \%)$ yang artinya pelatihan, motivasi dan disiplin kerja secara bersama mampu mempengaruhi kinerja karyawan sebesar $45,4 \%$ sedangkan sisanya $54,6 \%$ dijelaskan oleh variabel lainnya yang tidak diteliti dalam penelitian ini.

\section{PEMBAHASAN}

Hasil penelitian menunjukkan bahwa secara parsial pelatihan, dan disiplin kerja berpengaruh signifikan terhadap kinerja karyawan Dinas Pengamanan PT. Angkasa Pura Pekanbaru. Sedangkan motivasi tidak berpengaruh terhadap kinerja karyawan. Secara simultan pelatihan, motivasi dan disiplin kerja berpengaruh signifikan terhadap kinerja karyawan Dinas Pengamanan PT. Angkasa Pura II Pekanbaru. Nilai adjusted $R$ square dari model penelitian ini adalah 0,454 (45,4\%).

Ini membuktikan bahwa seluruh hipotesis diterima dan mendukung penelitian terdahulu yang memberikan kaitan antara variabel pelatihan dan disiplin kerja terhadap kinerja pegawai. Sebagaimana diuraikan oleh Lubis (2008) meneliti pengaruh pelatihan dan motivasi kerja terhadap kinerja karyawan PT. Perkebunan Musantara IV (Persero)
Medan. Populasi penelitian ini adalah seluruh karyawan pimpinan pria dan wanita di Kantor Pusat PT. Perkebunan Musantara IV (Persero) Medan yang berjumlah 155 orang. Hasil penelitian menunjukkan bahwa pelatihan dan motivasi kerja berpengaruh terhadap kinerja karyawan baik secara parsial maupun simultan. Nilai koefisien determinasi diperoleh sebesar $8,81 \%$.

Juga diperkuat oleh pendapat Sanjaya (2015) dengan judul penelitian pengaruh disiplin kerja dan motivasi kerja terhadap kinerja karyawan Hotel Ros In Yogyakarta. Populasi dalam penelitian sebanyak 115 orang karyawan Hotel Ros In Yogyakarta. Teknik sampel yang digunakan purposive sampling sehingga diperoleh sampel sebanyak 115 orang. Dari hasil penelitian menunjukkan bahwa secara parsial dan simultan disiplin kerja dan motivasi kerja berpengaruh positif dan signifikan terhadap kinerja karyawan.

Serta pendapat Rumbewas (2016) meneliti mengenai analisis pengaruh pelatihan, motivasi dan disiplin kerja terhadap kinerja karyawan (studi pada karyawan Bank BRI Kantor Wilayah Jayapura). Sampel sebanyak 70 orang menggunakan teknik purposive sampling. Metode analisis data yang digunakan adalah metode regresi linier berganda. Berdasarkan hasil penelitian ini menunjukkan bahwa variabel pelatihan, motivasi dan disiplin kerja berpengaruh positif terhadap variabel kinerja karyawan.

\section{SIMPULAN}

Berdasarkan uraian di atas secara parsial pelatihan, dan disiplin kerja berpengaruh signifikan terhadap kinerja karyawan sedangkan motivasi tidak berpengaruh terhadap kinerja karyawan. Secara simultan variabel bebas berpengaruh terhadap variabel terikat. 


\section{DAFTAR RUJUKAN}

Arikunto, S., 2006, Prosedur Penelitian Suatu Pendekatan Praktik, Ed Revisi VI, Penerbit PT Rineka Cipta, Jakarta.

Danang, Sunyoto., 2015, Manajemen dan Pengembangan Sumber Daya Manusia, CAPS, Jakarta.

Ghozali, Imam., 2001, Aplikasi Analisis Multivariate Dengan Program SPSS, Badan Penerbit Universitas Diponegoro, Semarang.

Kuswadi, 2004, Cara Mengukur Kepuasan Karyawan, Penerbit PT. Elex Media Komputindo, Jakarta.

Lubis, 2008, Pengaruh Pelatihan dan Motivasi Kerja Terhadap Kinerja Karyawan PT. Perkebunan Musantara IV (Persero) Medan, Tesis Universitas Sumatra Utara.

Mangkunegara, 2007, Evaluasi Kinerja SDM cetakan ke enam, Refika Aditama, Bandung.

Pratisto, Arif., 2004, Masalah Statistik dan Rancangan Percobaan dengan SPSS 12, PT.Elex Media Komputindo Kelompok Gramedia, Jakarta.
Riduwan, 2014, Metode \& Teknik Menyusun Proposal Penelitian, Alfabeta, Bandung.

Rumbewas, 2016, Analisis Pengaruh Pelatihan, Motivasi dan Disiplin kerja terhadap kinerja karyawan (studi pada karyawan Bank BRI Kantor Wilayah Jayapura), Tesis, Fakultas Ekonomika dan Bisnis.

Sanjaya, 2015, Pengaruh Disiplin Kerja dan Motivasi Kerja Terhadap Kinerja karyawan Hotel Ros In Yogyakarta, Skripsi, Universitas Negeri Yogyakarta.

Sugiyono, 2015, Metode Penelitian Manajemen, Alfabeta, Bandung.

Sutopo, 2006, Metodologi Penelitian Kualitatif, UNS, Surakarta.

Husein Umar, 2000, Riset Pemasaran dan Perilaku Konsumen Cetakan Ketiga, PT. Gramedia Pustaka Utama, Jakarta. 